\title{
LAS PRIORIDADES DE UN MONARCA ILUSTRADO: EL GASTO PUBLICO BAJO EL REINADO DE CARLOS III
}

\author{
JACQUES A. BARBIER y HERBERT S. KLEIN * \\ Universidad de Ottawa (Canadá) y Columbia University (USA)
}

Carlos III ha gozado tradicionalmente de gran estima entre los historiadores. Richard Herr expresaba el sentir de la mayoría de éstos cuando le describió como el rey que \&... hizo por España más que ningún otro monarca desde la reina Isabel la Católica», y al afirmar que «entre los déspotas ilustrados de su época, no hubo otro que alcanzara mayor éxito"' '. Su fama se extiende incluso a las finanzas públicas, ruina de muchas regias reputaciones ${ }^{2}$. Sin embargo, tan favorable interpretación debiera motivar cierta inquietud, particularmente en lo que concierne a los asuntos fiscales. Ciertos trabajos recientes se han mostrado más escépticos con respecto a su reputación en general, y cabe la posibilidad de que dicha estima se deba más a los conocidos objetivos modernizadores de este reinado que a sus realizaciones ${ }^{3}$.

Pues bien, ¿cuáles fueron las metas del gobierno de Carlos III? A pesar de que ciertas medidas no exigen gastos, se considera casi siempre que el presupuesto de un Gobierno moderno es un indicador primordial de sus objetivos. Lo mismo podría aplicarse a la España del Antiguo Régimen. En este caso, sin embargo, nadie ha intentado una valoración presupuestaria adecuada. Por el contrario, no obstante su opinión paradójicamente favorable sobre la cuestión, los historiadores no tienen una idea clara sobre las reales finanzas del reinado de Carlos III.

Puede que esta pesimista consideración sobre el estado de conocimiento de esta cuestión parezca exagerada. El especialista señalará de inmediato a la obra del siglo xIX que, en varios volúmenes, escribió José de Canga Argüelles, un autor con seguridad bien informado, habiendo trabajado en el Ministerio

* Los datos para este artículo fueron reunidos por el profesor Barbier con fondos de investigación del Canada Council y del Social Sciences and Humanities Research Council of Canada. El trabajo de análisis y elaboración se realizó con una beca (International Collaborative Research Grant) de esta segunda institución.

' Richard Herr (1958), p. 235.

2 Para un ejemplo de dicha opinión, véase Herr (1958), p. 380.

3 Este escepticismo en aumento puede verificarse fácilmente. Véanse, por ejemplo, David Ringrose (1973) y Barbara H. y Stanley J. Stein (1973). 
de Hacienda y la Tesorería General durante los últimos años del Antiguo Régimen ${ }^{4}$. Dicha obra es, no obstante, una defectuosa herramienta de valoración, ya que no proporciona sistemáticamente los datos ordenados en serie que exige una relación cuantitativa, si ha de ser significativa. Además, su insuficiente aclaración de las prácticas de contabilidad de la época supone una difícil interpretación de la información que ofrece. Por lo que respecta a las obras de historiadores actuales sobre la Hacienda, nadie ha hecho para el reinado de Carlos III lo que Josep Fontana ha realizado para el de Fernando VII; también hay que mencionar el estudio de J. P. Merino para el reinado de Carlos IV ${ }^{5}$. El resultado es que nuestras opiniones carecen de fundamento sólido. Didier Ozanam describió la situación, con toda la ecuanimidad posible, no hace mucho tiempo; aunque ésta algo ha cambiado recientemente:

"Or nous savons assez peu de choses sur les finances publiques de l'État espagnol du xvirI ${ }^{\mathrm{e}}$ siècle. Les rares chiffres du budget que nous possédons sont $[\ldots]$ tirés de Canga Argüelles ou de quelques économistes contemporaines (Ustáriz par example). Nous n'avons pas davantage une idée précise du système fiscal espagnol, depuis les réformes d'Orry au debut du règne de Philippe V: les exposés historiques généraux, ceux de Desdevises du Dézert, de Mounier ou de Vicens Vives, par example, son passablement confus et toujours puisés au mêmes traités. Non que ceux-ci, du à de bons spécialistes soient dépovours de valeur: mais ils restent à la fois incomplets et d'un maniement difficile, ce qui ne leur permet pas de répondre parfaitement aux exigences de notre moderne curiositém ${ }^{6}$.

Una respuesta adecuada a la curiosidad de nuestros días está, sin duda, fuera del alcance de un examen tan breve como el que sigue. Pero es tal la complejidad de las finanzas del Antiguo Régimen que dilucidarla ha de ser fruto de una indagación sistemática, de la cual éste sería un análisis parcial y preliminar, que acompaña a otros ya realizados en los últimos años ${ }^{7}$.

Este artículo está dedicado a la aclaración de una sola de las características de la política fiscal: la pauta seguida por el gasto desde 1760 hasta 1788 . $\mathrm{El}$ análisis de dicho gasto proporciona un índice razonable de las intenciones

4 José de Canga Argüelles (1826-27).

3 Josep Fontana Lázaro (1973 y 1974). El autor trata brevemente el siglo xviII en las pp. 13-42, pero sólo en lo relativo a las rentas públicas y a su recaudación. J. P. Merino (1981).

- Didier Ozanam (1966), p. 206.

7 Pueden citarse, como ejemplo, M. Artola (1982), Jacques A. Barbier y Herbert S. Klein (1981), J. Cuenca (1981) y las comunicaciones recogidas en Artola y Bilbao (1984). 
y los fines de la Corona, reflejados en la distribución de fondos entre las diversas áreas de la vida nacional. Además, dadas las prioridades así reveladas, el nivel general de fondos puestos a disposición de la acción estatal debe suministrar un cierto sentido de lo factible, una cierta comprensión del grado en que las restricciones financieras permitían una acción efectiva, en cuanto a los planes de cambio y desarrollo del reformador.

Este análisis del gasto del Gobierno español se fundamenta en la contabilidad de la Tesorería General, una institución en gran medida responsable de los desembolsos que cubrían las operaciones europeas de la Corona. Dicha contabilidad contiene la de la Tesorería Mayor de Madrid, así como las de diversas tesorerías regionales. Incluye también los gastos realizados en nombre del tesorero general por parte de toda una multitud de entidades de recaudación de rentas públicas. Pero no abarca la totalidad de estos casos. Entre otras excepciones, existía una Pagaduría de Juros independiente para ciertas porciones de la deuda pública, una Marina y una Casa Real administradas con criterios algo especiales, y corporaciones de la Corona semiautónomas. Pero, incluso en estos casos, los fondos tendían a pasar por la Tesorería General de camino a su destino final. No obstante las exclusiones, una mayoría abrumadora de los gastos corrientes están registrados en la documentación antes citada. Dicha contabilidad proporciona un vehículo aceptable para la reconstrucción de los gastos públicos en la España de fines del siglo xviII ${ }^{8}$.

Los legajos de las cuentas manuscritas del cajero principal de la Tesorería Mayor van acompañados de un «librete», que ofrece un útil resumen de los débitos («data») del año. En estos «libretes», los débitos están clasificados según los diversos «ramos" - las categorías de gasto ordenadas por la instrucción impresa de 1753, con mínimas alteraciones-. Además, cada uno de los ramos está a su vez dividido, enumerando en cada caso la suma gastada por las diferentes secciones del Tesoro $\mathrm{y}$, sobre todo, por otros organismos?.

Sea cual fuere su utilidad, hay que manejar estos «libretes» con precau-

- Para la ordenación con arreglo a la cual enumeraba y declaraba la Tesorería General prácticamente todo tipo de gastos, véase Instrucción para los thesoreros de exército, y provincia, $y$ depositarios y pagadores cuyas cuentas están mandadas comprebender en la del thesorero general, $y$ sobre la forma, y modo en que deben presentarlas (Madrid, 1753), del cual se conserva un ejemplar en Archivo General de Indias, Arribadas, leg. 524. En el texto se hace referencia a dicha ordenación como Instrucciones de 1753.

- Las tesorerías incluidas son: la Tesoreria Mayor (Madrid); la Depositaria de Indias (Cádiz, en dos respectos: Indias y Rentas); los Tesoreros de Ejército de Andalucía, Aragón, Castilla, Cataluña, Extremadura, Galicia, Mallorca y Valencia, y las Pagadurías de Orán, Ceuta y los Tres Presidios Menores (Málaga). 
ción. No todos los débitos representan gastos en sentido estricto. En el análisis que sigue se han excluido todas las transferencias de fondos de una parte de la Tesorería General a otra, para evitar contabilizarlas por duplicado. En efecto, era práctica española registrar semejantes sumas como débitos de la oficina que las transfería y volver a registrarlas cuando la oficina receptora, a su vez, las desembolsaba. De modo similar, las sumas registradas como saldo remanente para el año siguiente han sido eliminadas por no representar ni adquisición de bienes y servicios ni pagos de obligaciones.

Estas sencillas precauciones tienen la finalidad de garantizar que los datos de base no contengan elementos extraños. Pero el análisis exige un paso más, pues los 37 ramos de débito son excesivamente numerosos como para permitir un examen cómodo. Con este fin, han sido integrados en ocho grupos de gasto, conforme a su carácter individual. Son éstos: Casa Real, Administración Peninsular, Servicio Exterior, Ejército, Marina, Extraordinario, Débitos Excluidos y Deudas y Atrasos. En el apéndice 1 se ofrece una enumeración de los diversos grupos y los ramos que los componen, junto a una explicación de las secciones menos claras.

Por último, España experimentó a fines del siglo xvirI otro de sus periódicos brotes de inflación. El impacto de este fenómeno habría sido el de impulsar hacia arriba el gasto en términos corrientes, aun dándose niveles estáticos en los servicios. Para extirpar dicho factor se ha utilizado uno de los trabajos clásicos de Hamilton sobre la historia de los precios, para obtener los gastos deflactados ${ }^{10}$.

Una vez realizadas estas operaciones, existe una base firme para el examen del gasto público bajo Carlos III. Sólo se tratan los gastos, claro está. A pesar de lo cual, y dentro de sus límites, este ejercicio ofrece un panorama más nítido de las prioridades de su reinado que el conocido hasta ahora.

El rasgo más sobresaliente que revela el análisis del gasto total en términos constantes es que hubo una extraordinaria estabilidad en el gasto gubernamental desde 1760 a 1788 . En efecto, las únicas desviaciones dentro de este cuadro relativamente estático ocurrieron al inicio y al fin del reinado; los años $1760-1763$ y $1780-1783$ muestran, en ambos casos, niveles de gasto muy superiores a la tendencia general. La primera de estas breves elevaciones se debió, evidentemente, al desembolso de los fondos acumulados en el reinado anterior, dado que había la considerable suma de $\mathbf{2 7 0}$ millones de reales de vellón acumulados por Fernando VI, y fue parcialmente producto de las ne-

${ }^{10}$ Véase cuadro 1 , nota a, para el modo en que se deflactó. 
cesidades originadas por la renovación del Pacto de Familia y la breve participación de España en la Guerra de los Siete Años. El segundo fue el período de participación española en la Guerra de Independencia norteamericana, un conflicto que obligó al régimen a aceptar niveles de gasto peligrosamente elevados. Después de cada uno de estos puntos máximos de gasto, los débitos volvieron a dimensiones más normales: una tendencia descendente, irregular pero prolongada, tras el Tratado de París (1763), vio la caída del gasto total en términos reales, hasta su punto más bajo en 1774; inmediatamente después del Tratado de Versalles (1783), se realizaron denodados esfuerzos que devolvieron los gastos al nivel de la tendencia general que habían tenido antes de la guerra (véase gráfico 1 ).

Dos hechos se destacan. En términos de poder adquisitivo, la afortunada intervención de España en la Guerra de Independencia norteamericana costó un tercio más al año de lo que se estaba gastando en el primer quinquenio del reinado, que, a su vez, se había caracterizado por fuertes gastos iniciales de la Corte, envíos de sumas considerables a Nápoles y la desastrosa participación en la Guerra de los Siete Años. Teniendo en consideración el extraordinario nivel de actividad militar del país (con las operaciones de Menorca y Gibraltar, el despliegue naval en el Atlántico, las campañas de Florida y las Bahamas y la expedición Guarico), puede que este dato parezca moderado. Pero aun si se adoptara semejante punto de vista, lo que no puede parecer «moderado» es el aumento en términos monetarios, que supuso casi dos ter$\operatorname{cios}^{11}$. En efecto, mientras la Corona tenía que adquirir mercancías y servicios en un mercado relativamente abierto, sin protección - salvo en lo relativo a aspectos tales como los salarios - contra las presiones inflacionarias, sus ingresos provenían de impuestos que eran escasamente sensibles a semejantes factores.

En segundo lugar, como ya se ha señalado, en los años posteriores a 1783 el gasto descendió. El expendio real se redujo a un valor medio ajustado de 534.738 .000 reales de vellón -un 7,0 por 100 superior al de $1760-1764$ y sólo un 5,3 por 100 superior al de 1775-1779-. Este hecho nos permite llegar a una serie de conclusiones. Queda claro que la guerra no produjo un aumento permanente significativo en los gastos de la Hacienda en términos reales. Por el contrario, los desembolsos del gobierno no se elevaron mucho en términos ajustados con el índice de precios. Pero, sin embargo, la cantidad de efectivo que se necesitó se incrementó ligeramente por encima de una quinta parte con relación a los niveles anteriores a la guerra, y algo por debajo de dos quintos en relación con los primeros años del reinado ${ }^{12}$. Como ya

$" \mathrm{El}$ aumento es del 63,3 por 100 .

12 Los aumentos son del 21,8 por 100 , en comparación con 1775-1779, y del 38,5 por 100, en comparación con 1760-1764. 


\section{CUADRO 1}

Débitos de la Tesoreria General

(En miles de reales de vellón)

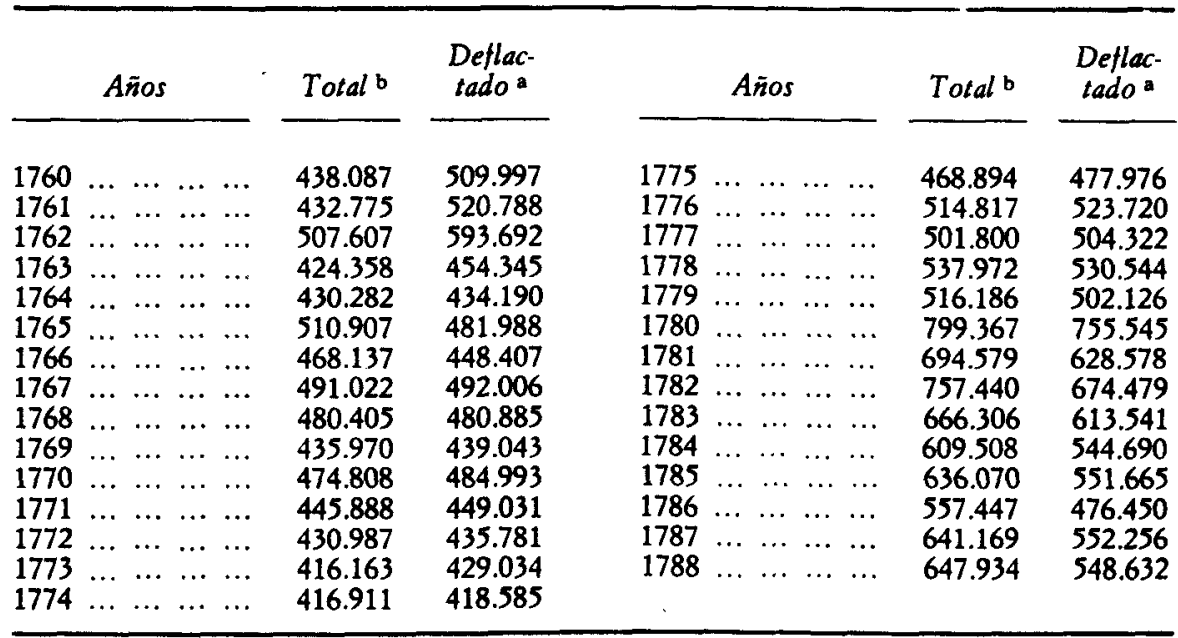

FUENTE: Véase apéndice 2.

\section{Notas:}

- Se ha deflactado empleando los números índice para Madrid proporcionados por Earl J. Hamilton en $W$ ar and Prices in Spain, 1651-1800 (Cambridge, Mass., 1947), p. 155. Estos son los siguientes:

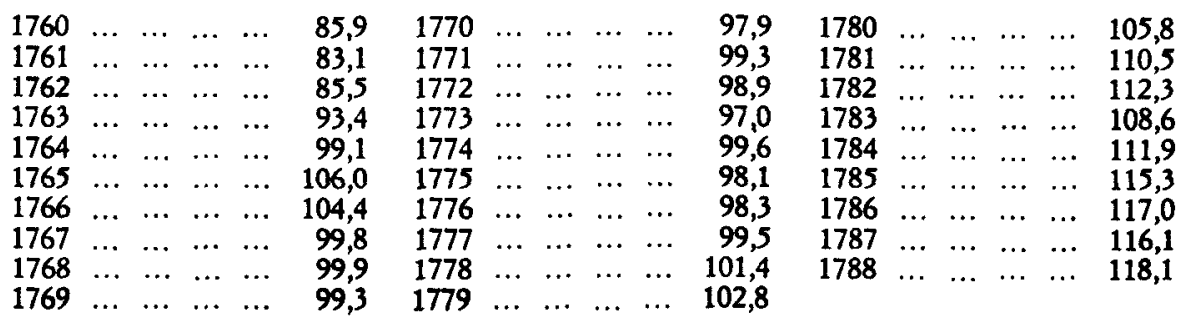

b En 1765.1769 se cargaron unos 270 millones de reales de vellón procedentes de los ahorros del llamado Real Depósito. Dicha suma se colocó allí en 1761-1764, iniciándose con una transferencia de $\mathbf{2 0 0}$ millones de reales de vellón sacados de la Depositaría de Indias como Extraordinario de Hacienda en 1761. Así, pues, parece que el dinero se cargó dos veces a cuenta. Para rectificar esta situación, las sumas enumeradas bajo Extraordinario de Hacienda, para 1761-1764, han sido reducidas en 270 millones de reales de vellón y se ha insertado la media para los cuatro años en lugar de las cantidades anuales. 


\section{GRAFICO 1}

Gastos totales ajustados

(Desviaciones con respecto a una tendencia logarítmica)

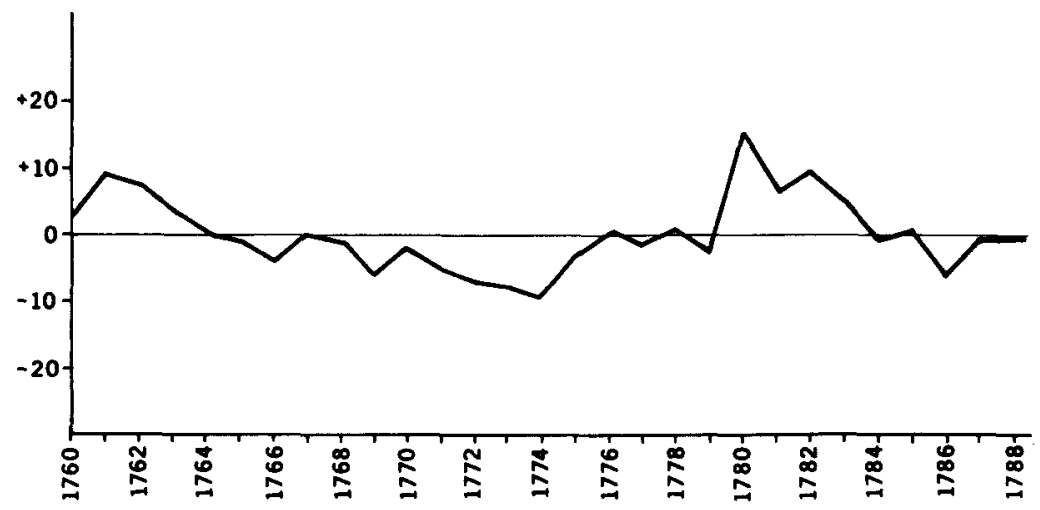

Fuente: Véase cuadro 1.

se ha dicho, el sistema tributario español, como el de otros Estados del Antiguo Régimen, tendía a responder con lentitud a la inflación, y el problema no se solucionaba, por consiguiente, automáticamente. Desde la perspectiva regia, el aumento de los ingresos era la solución más deseable al problema. Ello implicaba una recaudación más eficiente, ingresos más elevados debido a una mayor actividad económica o un más alto nivel impositivo, o intensificar la repatriación de fondos coloniales. Con respecto a esto último existe una sólida evidencia ${ }^{13}$. Pero no parece haber sido suficiente $y$, en cuanto a las restantes posibilidades, el éxito debió ser modesto, pues el gobierno español llevó a cabo un severo plan de austeridad en los años finales del reinado ${ }^{14}$.

Al observar los niveles generales del gasto y su interrelación, a lo largo del tiempo y a través de las distintas guerras coloniales, se hace evidente que los hábitos de gasto de la Corona estaban muy íntimamente correlacionados con las amenazas externas al Estado, y escasamente relacionados con cambios a largo plazo en la economía política de la nación. Pero esta última afirmación sólo puede quedar plenamente apoyada con un análisis detallado de los componentes de los gastos regios durante el reinado de Carlos III. Así, pues, la siguiente sección se propone determinar qué costes influyeron más en los cambios registrados en el gasto total del gobierno, así como fijar las opciones

${ }^{13}$ Véase Jacques A. Barbier (1981).

" Véase Jacques A. Barbier (1977). 
posibles para el gobierno a la hora de gastar en planes no tradicionales, especialmente aquellos relacionados con sus programas de reforma.

\section{III}

Se hace evidente de inmediato que el volumen mayor de los gastos de la Tesorería General se prodigó, desde el principio, sobre el área militar. Como puede comprobarse en el cuadro 2 , en el curso de este reinado, casi tres quintas partes de todos los gastos se dedicaron al mantenimiento del Ejército y la Marina. Esta proporción preponderante hizo de la estructura de defensa en su totalidad un aumento de crucial importancia a la hora de determinar las dimensiones generales del presupuesto, pero los gastos navales, por sí solos, fueron los máximos responsables de las alteraciones producidas en la salida de fondos con el paso del tiempo ${ }^{15}$.

\section{CUADRO 2}

Porcentajes de los gastos totales por tipos y por quinquenios

\begin{tabular}{|c|c|c|c|c|c|c|c|c|}
\hline Quinquenios & $\begin{array}{l}\text { Ejér- } \\
\text { cito }\end{array}$ & Marina & Extra. & $\begin{array}{l}\text { Casa } \\
\text { Real }\end{array}$ & Deudas & $\begin{array}{l}\text { Adm. } \\
\text { Pen. }\end{array}$ & $\begin{array}{l}\text { Déb. } \\
\text { Exc. }\end{array}$ & $\underset{\text { Ext. }}{\text { Serv. }}$ \\
\hline 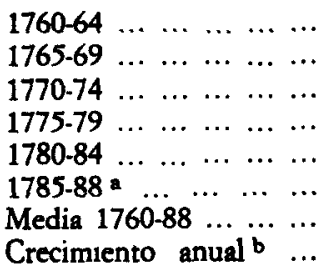 & $\begin{array}{c}34,9 \\
36,6 \\
44,4 \\
40,2 \\
31,8 \\
32,8 \\
36,3 \\
0,14\end{array}$ & $\begin{array}{l}20,8 \\
17,0 \\
21,0 \\
26,9 \\
29,3 \\
24,6 \\
23,8 \\
1,10\end{array}$ & $\begin{array}{r}11,3 \\
19,3 \\
3,8 \\
5,0 \\
11,1 \\
6,9 \\
9,7 \\
-0,86\end{array}$ & $\begin{array}{r}11,7 \\
10,1 \\
9,8 \\
8,9 \\
6,2 \\
8,0 \\
8,8 \\
-0,53\end{array}$ & $\begin{array}{c}7,7 \\
3,3 \\
5,6 \\
4,2 \\
10,2 \\
12,4 \\
7,4 \\
1,50\end{array}$ & $\begin{array}{l}7,4 \\
8,7 \\
7,8 \\
7,5 \\
5,2 \\
6,5 \\
7,0 \\
-0,60\end{array}$ & $\begin{array}{c}4,7 \\
5,2 \\
6,1 \\
6,1 \\
5,2 \\
7,6 \\
5,8 \\
-0,96\end{array}$ & $\begin{array}{l}1,4 \\
1,3 \\
1,4 \\
1,3 \\
1,1 \\
1,3 \\
1,3 \\
0,04\end{array}$ \\
\hline
\end{tabular}

Notas:

a Sólo cuatro años.

b Tasas de crecimiento anuales en porcentajes.

${ }^{15}$ El coeficiente de correlación del gasto de Marina con el general es de 0,78 , y el único otro factor con un coeficiente que alcanza al 0,50 con relación al total es el de Deudas y Atrasos. Obsérvese que todos los coeficientes de correlación citados en este artículo se obtuvieron empleando valores deflactados. 


\section{GRAFICO 2}

Gastos totales del Ejército y de la Marina ajustados

(Desviaciones con respecto a una tendencia logarítmica)

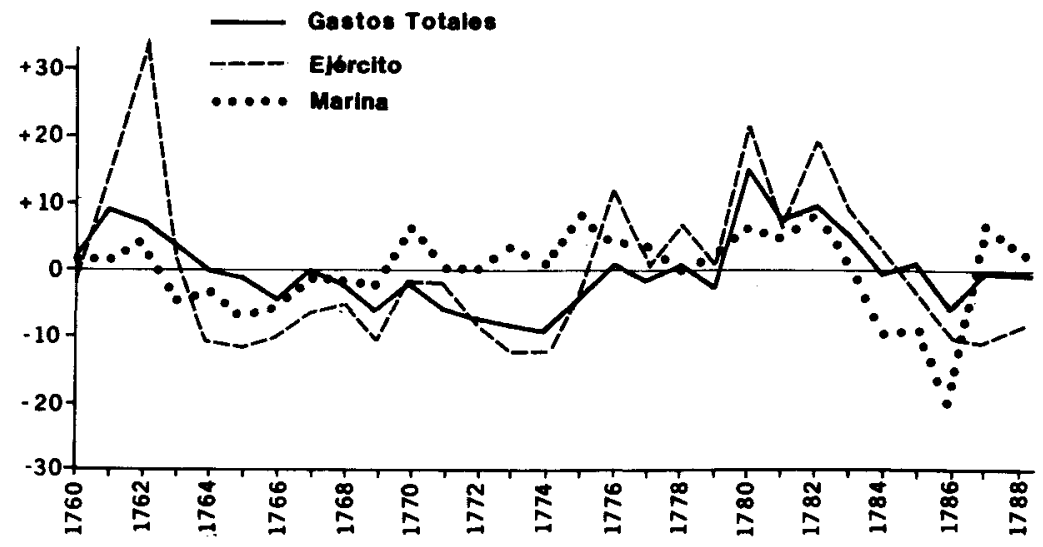

Furnte: Véase apéndice 2.

En efecto, hay que subrayar la importancia de los gastos de la Marina. El gráfico 2, que aparece más adelante, muestra el alto nivel de coincidencia existente entre los desembolsos de este ramo y el gasto total, así como la previsible relación entre períodos de contienda y elevados costes de la flota. Así, pues, los gastos de la Marina se encuentran muy por encima de la línea de tendencia sólo durante la Guerra de los Siete Años y la Guerra de Independencia norteamericana y a fines de la década de 1770, durante las hostilidades no declaradas en el Río de la Plata. Dado que las guerras coloniales ocasionaban un fuerte gasto naval, y este tipo de débito fue, con el tiempo, el factor más importante en modelar la configuración de los gastos totales, es fácilmente comprensible que las finanzas públicas españolas estuvieran sometidas a los sucesos americanos. Era ésta, no obstante, una situación apropiada para los reformadores borbónicos, los cuales habían abrigado durante mucho tiempo la esperanza de que los mercados y las minas de las Indias volvieran a hacer poderosa a la Monarquía e hicieran vibrar la economía peninsular ${ }^{16}$. Bajo esta perspectiva, los gastos navales representaban una inversión.

Puede sorprender que los gastos del Ejército estén tan sólo ligeramente

${ }^{16}$ Para un examen de la contradicción última entre estos componentes políticos y económicos de la política colonial, véase Jacques A. Barbier (1980). 
correlacionados con los gastos totales. Su débil, pero negativa, correlación con ramos como Casa Real y gastos Extraordinarios puede acaso proporcionar una mínima parte de la respuesta a este enigmático fenómeno, dado que ciertos gastos podían desplazarse fácilmente desde éstos al Ejército, y viceversa ${ }^{17}$. En medida mucho mayor, por supuesto, es sencillamente un testimonio de la estabilidad del compromiso de la Corona con las fuerzas de tierra, pues aunque la tasa de crecimiento anual fue un simple 0,14 por 100 , el Ejército, no obstante, recibió una media del 36,5 por 100 de los gastos anuales de la Hacienda a lo largo de todo el período. En todo caso, nada debe oscurecer el hecho de que el Ejército fue el gasto más importante de la Monarquía en todos los años del reinado, a excepción de uno (en 1784, el gasto naval fue superior), y sirvió, en consecuencia, como base amplia y de suave elevación para el resto del presupuesto. Esta sencilla cronología de los gastos del Ejército refleja esta función. Tras un máximo moderado en el gasto ajustado con precios, en 1762, los gastos tendieron a elevarse de forma relativamente regular desde mediados de la década de 1760 en adelante, hasta alcanzar otro techo en 1782. Hacia 1770, la Corona gastaba más en el Ejército de lo que había hecho en la Guerra de los Siete Años y, dado que dichos gastos permanecieron en gran medida por encima de la línea de tendencia en los años siguientes, cabe concluir que su escasa correlación con el gasto total se debe, simplemente, al hecho de que llegó a su nivel de la Guerra de Independencia norteamericana de modo más gradual que otros ramos del gasto. Efectivamente, el único rasgo destacable en la cronología de los gastos del Ejército es la súbita reducción que caracteriza los años 1784-1786. Para entender los origenes de esta economía presupuestaria, sin embargo, hay que dirigirse a otras dos categorias del gasto de la Hacienda.

Aparte de la Marina, los elementos que mejor explican las variaciones a lo largo del tiempo de los débitos totales son los de Deudas y Atrasos y gastos Extraordinarios ${ }^{18}$. Estos últimos alcanzaron niveles elevados en la década de 1760 y, nuevamente, en 1780 . Al parecer, la animación del primer quinquenio y de la década final del reinado fueron reflejo o resultado de la Guerra de los Siete Años y la Guerra de Independencia norteamericana. El motivo de la actividad en los gastos Extraordinarios de 1765-1769, sin embargo, es poco claro, y dilucidar esta cuestión exigiría una indagación que sobrepasaría con mucho la información proporcionada por los «libretes*. En todo caso, es seguro que se estaban realizando importantes acciones financieras bajo esta rúbrica en los años 1760 y 1780 , pero que los años 1770 fueron muy tranquilos.

1 Los coeficientes de correlación son 0,32 para el Ejército con el total, - 0,30 para Ejército con Casa Real y - 0,30 para Ejército con gastos Extraordinarios.

12 Los coeficientes de correlación son 0,58 para Deudas y Atrasos con el total y 0,46 para Extraordinarios con el total. 
Con respecto a Deudas y Atrasos, dicho grupo se caracterizó por unos niveles en descenso hasta mediada la década de 1770 , si bien se produjo una gran elevación en 1770-1772, que es tan inexplicable como la registrada en los gastos Extraordinarios a fines de los años 1760 (véase gráfico 3, más adelante). A partir de aquel punto tendió al alza, presentando la década de 1780 niveles muy superiores. Así, pues, la media con precios ajustados de 1760 . 1769 fue de 27.102 .012 reales de vellón; la de $1770-1779$, de 23.055 .400 reales de vellón; mientras que la media de $1780-1788$ fue de 65.390 .654 reales de vellón. La conclusión obvia es que el coste de financiación de los déficit del Tesoro, cuya importancia cayó hasta aproximadamente 1775 , se había elevado otra vez hasta niveles considerables hacia los años 1780 .

Parece claro que el impacto de la guerra tuvo efectos que superaron con mucho los límites de los gastos de la Marina y el Ejército. El gasto deficitario mientras perduraron las hostilidades suponía que había que contraer deudas. El interés y el principal de estas últimas habian de ser, inevitablemente, pagados en años subsiguientes. Del mismo modo, las hostilidades originaron gastos extraordinarios que, si bien relacionados con el esfuerzo bélico, no siempre encajaban en los definidos ramos de gasto adscritos al sector militar. $Y$, de modo similar, después o durante el conflicto, pudieron presentarse obligaciones a la Corona que los funcionarios del Tesoro decidieran incluir bajo la rúbrica de gastos Extraordinarios en lugar de bajo Deuda. El resultado fue que la guerra vio un incremento de los gastos totales muy superior al que podría explicarse por un aumento de los gastos puramente militares, y que los efectos del impacto que tuvo la contienda siguieron sintiéndose en los años que siguieron.

¿Significa el hecho de que la guerra absorbiera una parte tan considerable de los ingresos que no se realizaron verdaderas reformas? Existen al menos dos indicadores de signo posiblemente contrario: un ahorro apreciable en la Administración civil y una interesante pauta de gasto en los Débitos Excluidos. En cuanto al primero, los gastos de la Casa Real, Administración Peninsular y Servicio Exterior eran los menos importantes dentro del presupuesto del Estado; muestran la menor correlación con los gastos generales, se encuentran entre los cuatro que se correlacionan más débilmente con el paso del tiempo y, por último, su proporción conjunta dentro de los gastos generales descendió sostenidamente hasta después de la Guerra de Independencia norteamericana ${ }^{19}$. Parecería que la Corona logró reducir la burocracia y, para un Estado

1 Véase cuadro 2. Los coeficientes de correlación con el total son: -0,16 para Ćaea Real, - 0,05 para Administración Peninsular y 0,26 para Servicio Exterior; mientra que con el tiempo son - 0,67 para Casa Real, -0,20 para Administración Peninsular y 0,05 para Servicio Exterior. 


\section{GRAFICO 3}

Servicio de la Deuda y Gastos Excluidos ajustados

(Desviaciones con respecto a una tendencia logarítmica)

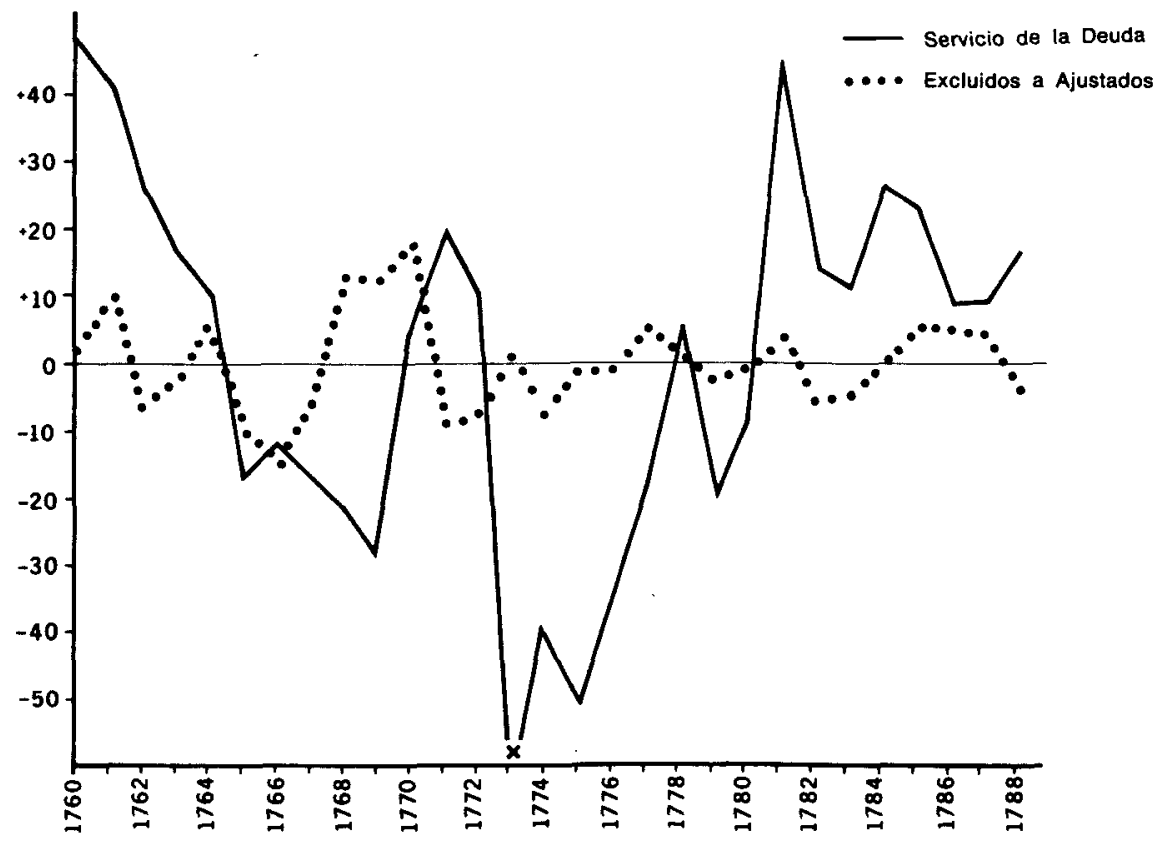

FUENTE: Véase apéndice 2

del Antiguo Régimen, esto representaba verdaderamente una reforma. Sin embargo, fue un logro esencialmente negativo.

La segunda zona clave que ha de examinarse con respecto a la capacidad reformista del régimen es su actividad en la promoción de obras, manufacturas y otras infraestructuras en pro del crecimiento económico. A pesar de que el ramo de Débitos Excluidos es complejo, pues está formado por numerosos negociados autónomos y contabilidades especiales, que no siempre representaban una inversión estatal directa en la economía, es, no obstante, el mejor indicador de dicha acción, puesto que, cualquiera que fuera la inversión, ésta provenía de estos negociados. La mayor dificultad, claro está, reside en que esta clase de gasto no estaba en modo alguno limitado a dichas cuestiones, e inclúa anticipos a los tesoreros y pagadores mayores encargados del mantenimiento y la construcción de los diversos palacios del rey. Pero esto es, en sí 
mismo, un dato bastante significativo, pues, como es bien sabido, muchas de las fábricas reales, en especial las de tapices y arañas de cristal, orientaban su actividad hacia los mercados de la Corte. En todo caso, los Débitos Excluidos no pueden resolverse en datos más significativos sin buscar un tipo de información que no está recogida en los «libretes».

Dejando por el momento a un lado el problema inherente a los datos, ¿qué revela el análisis? En el aspecto negativo, este ramo está sólo levemente correlacionado con los gastos totales $y$, dado que supone un 5,8 por 100 de la suma general, alcanza un simple séptimo lugar dentro de las ocho variables. Por último, como revela el gráfico 3, los Débitos Excluidos variaron, en realidad, escasamente sobre su línea tendencial con el paso del tiempo. Así, pues, a excepción de una ligera elevación en 1768-1770 y un descenso aún más reducido inmediatamente antes, la pauta general es de una creciente regularidad ${ }^{20}$. Esto podría llevarnos a concluir que los gastos reales dentro de este ramo no respondían a los posibles cambios de prioridad del Gobierno. En el aspecto positivo, sin embargo, tuvo la tasa mayor de crecimiento, después de Deudas y Atrasos y gastos de Marina, y la correlación máxima con el paso del tiempo ${ }^{21}$. En pocas palabras, aunque su importancia no fue grande, los Débitos Excluidos, efectivamente, aumentaron y, mientras que los gastos tendieron a ser relativamente uniformes, dicha regularidad fue de dirección progresiva.

¿Revelan los Débitos Excluidos de la Corona un compromiso con la reforma ilustrada? Tomando en consideración la incertidumbre que rodea la relación entre esta clase de gasto y la inversión gubernamental, así como el ambiguo resultado del análisis, se siente la tentación de ofrecer un veredicto de «no demostrado». Sea como fuere, su escasa participación en el presupuesto nos obliga a concluir que, por reformista que fuera la administración de Carlos III, la predisposición real a gastar con el fin de realizar cambios fue limitada.

En un artículo publicado en el Journal of European Economic History, sus autores concluían que en la esfera económica «[...] la actividad pública parece haber tenido numerosos fallos que tendieron a oscurecer sus modestos éxitos», hasta tal punto que «entre el crecimiento económico general y las empresas del Estado [...] existía una relación inversa» ${ }^{2}$. A pesar de todo, los autores de esta excelente contribución creyeron necesario incluir una concesión (presumiblemente ritual) a la opinión tradicional, al repetir la idea

20 Véase cuadro 1. El coeficiente de correlación de Débitos Excluidos con el total es 0,28 .

${ }^{21}$ Véase cuadro 2. El coeficiente de correlación de Débitos Excluidos con el tiempo es 0,79 .

"Agustín González Enciso y José Patricio Merino (1979), p. 590. 
ortodoxa de que «el fomento de la industria fue, desde el comienzo mismo, casi una obsesión para los gobiernos ilustrados ${ }^{23}$. Sin embargo, nuestro análisis del presupuesto de Carlos III, mientras que proporciona nuevos argumentos para creer en los fallos, no revela huella alguna de la obsesión.

Es cierto que una gran proporción del gasto militar debió dirigirse hacia obras y adquisiciones que iban en apoyo directo de la industria nacional. El ritmo y la oportunidad de estos gastos, sin embargo, no guardaban relación con consideraciones reformistas, sino que respondían, por el contrario, a preocupaciones de tipo internacional. Así, la construcción de una moderna Marina Real, importante para la industria naviera y numerosas industrias relacionadas, se realizó debido a una política originada por ciertas empresas coloniales antes que como respuesta racional a necesidades económicas nacionales. En líneas generales, la situación es paradójica. Empleando criterios de la época, incluso la modesta rectificación de la dirección del gasto gubernamental que se puede inferir pudo considerarse un importante indicador de "reformas» logradas. Utilizando criterios más modernos, el gobierno de Carlos III no dejó en sus presupuestos un espacio de importancia para inversiones en el desarrollo económico. Puesto que no tenía claras objeciones filosóficas a este tipo de intervención estatal, dicha laguna puede entenderse como una clara indicación de sus prioridades.

\section{IV}

Nuestra línea de argumentación hasta el momento se ha fundamentado en los movimientos generales del gasto de la Hacienda Real a lo largo del tiempo. Sería inútil examinar dichas tendencias a la luz de los cambios ministeriales y las carreras de las principales figuras políticas, para comprobar si sus diversas medidas tuvieron algún impacto sobre la estructura del gasto. Este problema tiene dos dimensiones: la cartera de Hacienda, por un lado; la posición extraoficial del ministro «principal», por otro. $Y$ ha de examinarse tanto en términos de las desviaciones del gasto total con respecto a la tendencia general, como aparece en el gráfico 1, como atendiendo debidamente la evolución de los débitos en términos reales ajustados con precios, véase gráfico 4, que aparece más adelante ${ }^{24}$. Con respecto a los ministros de Hacienda, tras el alza de comienzos del reinado, el período del marqués de Esquilache (1760-1766) estuvo caracterizado por un sostenido descenso en relación a la línea tendencial, pero sin un patrón perceptible en los gastos reales. La transición

${ }^{23}$ Ibid., p. 566.

24 Para fines analíticos, se consideró que los períodos comenzaban el 1 de enero siguiente a su verdadero inicio y terminaban el 31 de diciembre siguiente a su verdadero fin. 
desde la caída de Esquilache al conde de Gaussa (Múzquiz, 1767-1785) sí experimenta un breve aumento en Débitos Excluidos, pero es, por lo demás, insignificante. La periodización interna de este largo ministerio respondió al flujo y reflujo de las crisis externas, bajo la colérica batuta de Gaussa hasta su muerte. El conde de Lerena (1786-1788) empezó a prestar sus servicios a fines del reinado, y la serie estadística es excesivamente breve para ofrecer una información significativa. El incremento en los gastos de 1787-1788 puede atribuirse en gran medida a que aumentaron los gastos del Ejército. Ello

\section{GRAFICO 4}

\section{Gastos totales}

(En millones de reales de vellón)

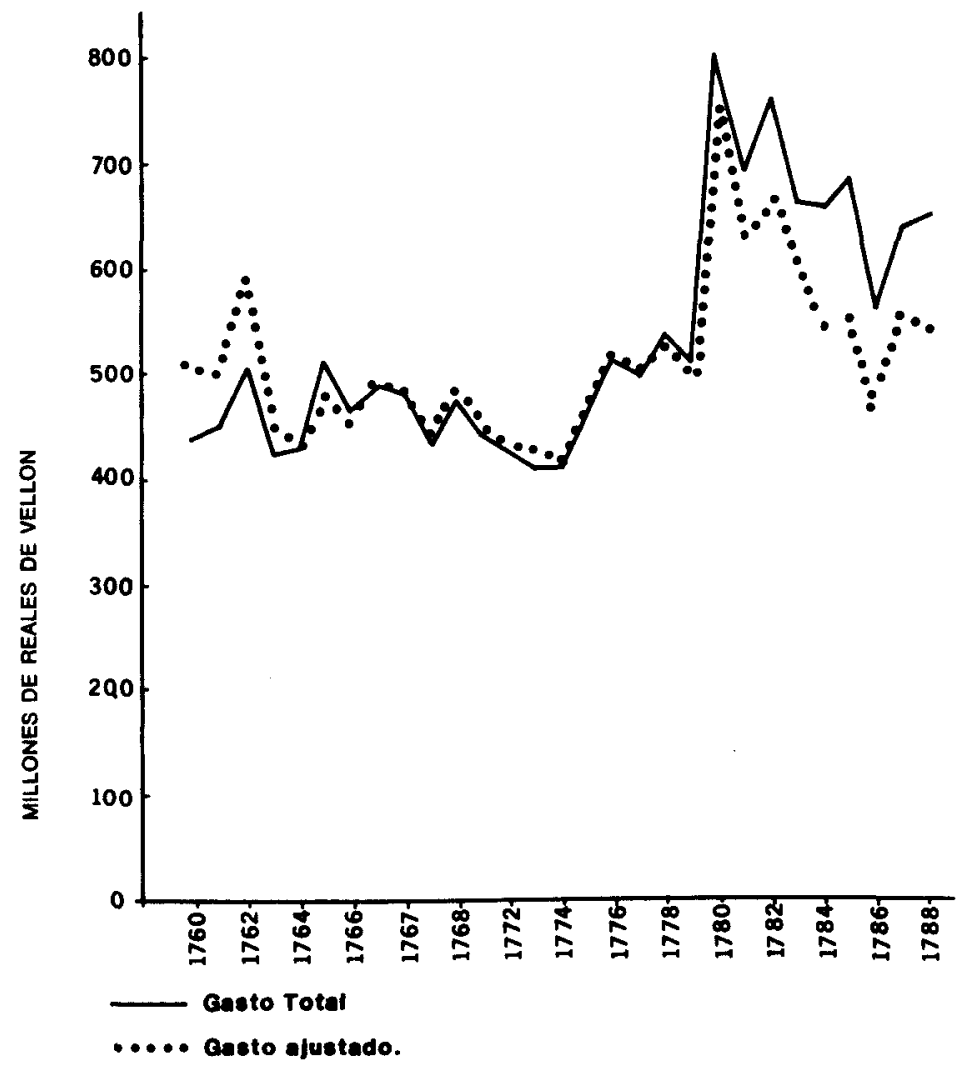

Fuente: Véase cuadro 1. 
fue, a su vez, casi totalmente resultado de mayores desembolsos para las «reales provisiones» del Ejército en estos años ${ }^{25}$.

Tampoco puede deducirse gran cosa de los períodos de los ministros «principales». El período de Ricardo Wall (1760-1762) es en exceso breve, y demasiado peculiar por ser en el comienzo del reinado, para poder analizarlo, y la sucesión del marqués de Grimaldi (1763-1776) por parte del conde de Floridablanca (Moñino, 1777-1788) no representa una línea divisoria en las finanzas. Ni es tampoco significativo el efímero mandato del conde de Aranda como presidente del Consejo de Castilla. Tan sólo queda suponer que los altibajos de las carreras políticas no tenían gran relación con las ordenadas alteraciones en las prioridades de gasto de la Corona.

Pero, sin embargo, dichas alteraciones eran significativas. La interpretación del periodo $1760-1764$ se hace, sin duda, más difícil e insegura por la falta de información precisa sobre el Real Depósito ${ }^{26}$. La contabilidad es mucho más clara a partir de 1765 . Empleando medias móviles trienales para el período 1766-1787, se descubre una pauta relativamente sencilla de descenso continuo hasta 1774, un aumento sostenido hasta 1781 (salvo en 1778) y una vuelta al descenso a partir de esta fecha (nuevamente, con la excepción de 1786) ${ }^{27}$. La curva de desviaciones de los gastos registrados del gráfico 1 revelan la misma tendencia.

Se podría considerar de modo provisional que en la década de 1760 preocuparon los legados fiscales del reinado de Fernando VI en Madrid y del gobierno de Carlos III en Nápoles (como Carlos VII), y el impacto de la Guerra de los Siete Años. Así, los gastos Extraordinarios de la primera década del mandato de Carlos III fueron probablemente resultado de prácticas conocidas, tales como el envío de dinero a Nápoles y el pago de las deudas de Fernando VI (pues aquel monarca dejó impagados a sus acreedores, y a los de su padre, a pesar de lo que atesoró). En todo caso, como ya se ha señalado, el período estuvo caracterizado por un declinar en los débitos, que se continuó a lo largo de los primeros años de la década de 1770 , mientras se resolvían los problemas iniciales del reinado.

${ }^{25}$ Obsérvese que se encargaba este servicio al Banco Nacional de San Carlos. Véase Orden de 27 noviembre 1786, en A. Matilla Tascón (1950), núm. 3791.

26 Véase cuadro 1 , nota $b$.

${ }^{27}$ Las cifras son (en miles de reales de vellón):

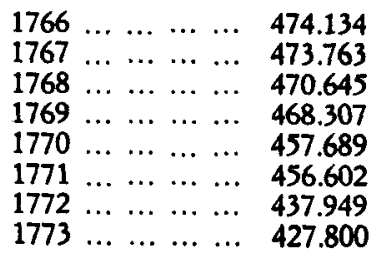

$1774 \ldots \ldots \ldots \ldots+44.865$

$\begin{array}{llllll}1775 & \ldots & \ldots & \ldots & \ldots & 473.427\end{array}$

$\begin{array}{llllll}1776 & \ldots & \ldots & \ldots & \ldots & 502.006\end{array}$

$\begin{array}{llllll}1777 & \ldots & \ldots & \ldots & \ldots & 519.529\end{array}$

$\begin{array}{llllll}1778 & \ldots & \ldots & \ldots & \ldots & 512.331\end{array}$

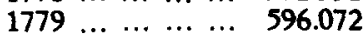

$\begin{array}{llllll}1781 & \ldots & \ldots & \ldots & \ldots & 686.201\end{array}$

$\begin{array}{llllll}1782 & \ldots & \ldots & \ldots & \ldots & 638.886\end{array}$

$\begin{array}{llllll}1783 & \ldots & \ldots & \ldots & \ldots & 6 \\ 1784 & \ldots & \ldots & \ldots & \ldots & 6108\end{array}$

$\begin{array}{llllll}1784 & \ldots & \ldots & \ldots & \ldots & 569.965\end{array}$

$\begin{array}{llllll}1785 & \ldots & \ldots & \ldots & \ldots & 524.268\end{array}$

$\begin{array}{llllll}1786 & \ldots & \ldots & \ldots & \ldots & 524.268 \\ & \ldots 26.790 & \ldots & \end{array}$

$1780 \ldots \ldots .6 .6 .628 .750$

$\begin{array}{llllll}1787 & \ldots & \ldots & \ldots & \ldots & 525.779\end{array}$ 
El período de 1775-1779 fue de rearme militar. En este caso, el elemento decisivo, como se muestra en el cuadro 2, no fue tanto el gasto en el Ejército mismo como el rápido incremento en los débitos de la Marina. Estos años se destacan también, claro está, por las expediciones a Argel y Río de la Plata.

En 1780-1783, España participó en la Guerra de la Independencia norteamericana. Como cumple a una contienda en gran medida colonial, el gasto de la Marina se aproximó mucho al del Ejército -al cual superaría en 1784 (véase apéndice 2)-. Es también digno de mención que se incluyeran fuertes desembolsos bajo gastos Extraordinarios, particularmente en 1780. También aquí es necesaria más investigación, pues está claramente implicada una gran operación conocida como la «real negociación extraordinaria». Este complejo plan abarcaba elementos tan diversos como la plata americana, anticipos a las autoridades coloniales francesas, negociación de letras de cambio y varios préstamos (entre ellos, la primera emisión de vales reales) ${ }^{28}$.

Los últimos cinco años del reinado, 1784-1788, exhibieron un intento de volver a niveles de gasto más normales. Pero, a causa de la inflación, fue imposible reducir los débitos reales a su volumen anterior a la guerra. Por otra parte, los débitos ajustados sí decayeron hasta un punto tan sólo moderadamente superior a los de los años 1770 . El gasto naval siguió representando una pesada carga, permaneciendo un 15,8 por 100 por encima del último quinquenio anterior a la guerra. Ello puede acaso explicar el creciente interés del Gobierno español en hacer que las colonias costearan la flota. El elemento más significativo dentro de los gastos de esta última fase del reinado, sin embargo, puede muy bien ser el de los costes en aumento de Deudas y Atrasos, que fueron más elevados que nunca tanto en términos porcentuales como de cifras absolutas.

Sea como fuere, es claro que las prioridades en el gasto no se debieron a los cambios ministeriales, y que dichos cambios no alteraron la dirección establecida por la Corona. El rumbo tomado por España en la vida internacional, y en consecuencia adoptado en las finanzas, era a un tiempo decisión del Rey mismo y cuestión de consenso entre sus principales consejeros. $Y$ ese rumbo estuvo más caracterizado por un deseo de seguridad del Estado y del régimen que por la inclinación a sactificar dicho interés a una reforma de corte ilustrado.

* Para ampliar sobre este asunto en particular, véase James A. Lewis (1980). 
En conclusión, se puede argumentar que el reinado de Carlos III estuvo caracterizado por un sincero anhelo de responder a lo que se consideraba como la responsabilidad de España como potencia colonial. Con este fin, al parecer, se superaron gradualmente dos graves problemas - las confusas finanzas del reinado anterior y el coste de una guerra prematura - en los primeros años de su gobierno. Hacia 1775, el Rey pudo incrementar de modo importante sus gastos navales $y$, durante el estallido de la guerra de 1779, acelerar intensamente los preparativos. Pero la guerra fue mucho más costosa de lo que podría pensarse examinando simplemente los débitos del Ejército y la Marina. Dejó tras de sí una fuerte deuda cuya carga malamente podía soportar el Gobierno. Finalmente, esta dificultad se vio acentuada por la inflación y, en última instancia, quedó agravada por la tendencia de la Administración a resolver sus problemas con una creciente dependencia de las entidades semioficiales de crédito (Banco Nacional de San Carlos, Cinco Gremios Mayores de Madrid, etc.), que acabó por arrastrar consigo a la ruina.

Sería falso afirmar que Carlos III hundió a España en el mismo abismo al que Luis XVI llevó a Francia. Pero no se puede negar, sin embargo, que el «déspota ilustradow llegó muy cerca del borde por el que se despeñaría Carlos IV, y el motivo de este empeoramiento de la situación, si hemos de juzgar por las pautas seguidas por el gasto de su Hacienda, fue que sus prioridades tenían relación con la guerra $\mathrm{y}$, ante todo, con la guerra imperial.

Lo que demuestra nuestro análisis de esta contabilidad es la necesidad de que el historiador revise seriamente su concepción del potencial reformador de la Monarquía más ilustrada del Antiguo Régimen. En España, las enormes sumas gastadas en las fuerzas armadas, y las cantidades necesitadas para pagar guerras anteriores, limitaron, evidentemente, la capacidad de la Corona para dirigir fondos hacia nuevas empresas, y aunque las colonias aportaron, sin duda, ingresos a la economía metropolitana, es posible que no fueran tan importantes como podría haber requerido una inversión pública bien administrada (o una aligeración de la carga fiscal).

Es bien sabido de los historiadores que la Corona fomentó la iniciativa privada. Incapaz de invertir con cierta garantía en desarrollo, no podía hacer menos. También coadyuvó a crear una estructura legal de apoyo y a proporcionar un clima propicio para la inversión privada. Pero no estuvo en sí misma interesada en aumentar su propia inversión directa en dicha economía, ni en reorientar su actividad tradicional hacia una intensificación del desarrollo económico de la nación. En efecto, respondió más a sus intereses internacionales como potencia de primera magnitud y altura imperial, papel más bien 
tradicional de la Monarquía castellana a partir del siglo xvi. Así, pues, no sólo estuvo limitada su capacidad para dirigir fondos hacia las obras públicas no militares por su dedicación al sistema de defensa, sino que dicho sistema y sus necesidades parecieron también dictar decisiones políticas a largo plazo, al menos en lo que respecta a los gastos regios. 
APENDICE 1

Grupos de gasto y ramos de débito que los constituyen

A. Casa Real a Casas y Caballerizas Reales Amas

B. Administración. Peninsular b Secretarías del Despacho y Tesorería Mayor

Ministros y Tribunales

Pensiones de Hacienda

Ministros de Hacienda y Guerra

Pensiones de Guerra

Montepío Militar y del Ministerio

C. Servicio Exterior

Ministros en Cortes Extrangeras

D. Ejército b

Menages y Vestuarios

Provisiones y Viveres

Guardias de Corps y Alabarderos

Guardias Españolas y Walonas

Infantería, Inválidos, y Milicias

Regimiento Real de Artillería

Estados Mayores de Artillería

Caballería y Dragones

Estados Mayores de Plazas

Oficiales Generales

Diferentes que no Sirven en Cuerpos
Ingenieros

Viudas de Seis Mil Doblones

Viudas de Dos Pagas y Limosnas

Familias de Orán y Moros de Paz

Sueldos y Gastos de Hospitales

Fortificaciones y Artillería

Extraordinario de Guerra

E. Marinac

Sueldos y Gastos de Marina

Tesoreros de Marina y Pagadores de Guerra

F. Gastos Extraordinarios d

Extraordinario de Hacienda

Incongruos

G. Débitos Excluidose

Tesoreros y Pagadores de Hacienda

H. Deudas y Atrasos

$5 \%$ de Real Empréstito, $4 \%$ de Va. les Reales y Extinción

$3 \%$ de Juros y Censos y Recompensas

Cartas de Pago de Tesorería General Antecedente

Créditos de Testamentaría

$3 \%, 7 \%$ y $8 \%$ Sobre la Renta de Tabaco

algunos de estos gastos se esconden bajo «Extraordinario de Hacienda (manufacturas de joyas reales, alimentación de los reales jabalíes de El Pardo, etc.), «Tesoreros y Pagadores de Haciendaw (fondos adjudicados a diversos pagadores ordinarios y extraordinarios de los reales sitios) y «Menages y Vestuarios» (pagos a ciertos proveedores de los reales sitios).

b Incluye diversos tipos de pensiones a ex funcionarios, sus viudas, etc. Cualquiera de aquéllas con alguna vinculación a lo civil, aun si parcialmente relacionada con lo militar, se situaba bajo «Administración Peninsular». Las pensiones exclusivamente militares se enumeraban bajo «Fuerzas Militares», pero hay que señalar que la ayuda a los colonos de Orán se consideraba un asunto perteneciente al Ejército.

c El ramo titulado aTesoreros de Marina y Pagadores de Guerraw reagrupa en gran medida los débitos a los tres tesoreros navales de El Ferrol, Cádiz y Cartagena. Cuando consta que el débito tenía como destinatario a otro funcionario (pagador de Mahón, de la costa de Granada, de Ceuta o de una expedición), esto queda registrado.

d Incluye toda una variedad de gastos; entre ellos, algunos que guardan, realmente, relación con «Casa Real», «Administración Peninsular» (por ejemplo, el coste de las letras de cambio, transporte de moneda, impresión), «Débitos Excluidos» (por ejemplo, adquisición de servicios para las reales fábricas) y «Deudas y Atrasos», así como gastos auténticamente extraordinarios y secretos.

e Incluye los pagos hechos a los pagadores cuya contabilidad no se hallaba resumida en la de la Tesorería General, entre ellos los de varias reales fábricas y reales sitios. También incluye los débitos destinados al pagador de Minas de Almadén, pagador del Soto de Roma, comisario de Empaque de Azogues en Sevilla y depositario de los Reales Derechos y Caudales de Indias en Cádiz. Dado que todos estos pagadores podían también contar con ciertas sumas dentro de los ramos normales, puede considerarse este tipo de gasto como una especie de miscelánea. 


\section{APENDICE 2}

Débitos de la Tesorería General por grupos de gasto

(En miles de reales de vellón)

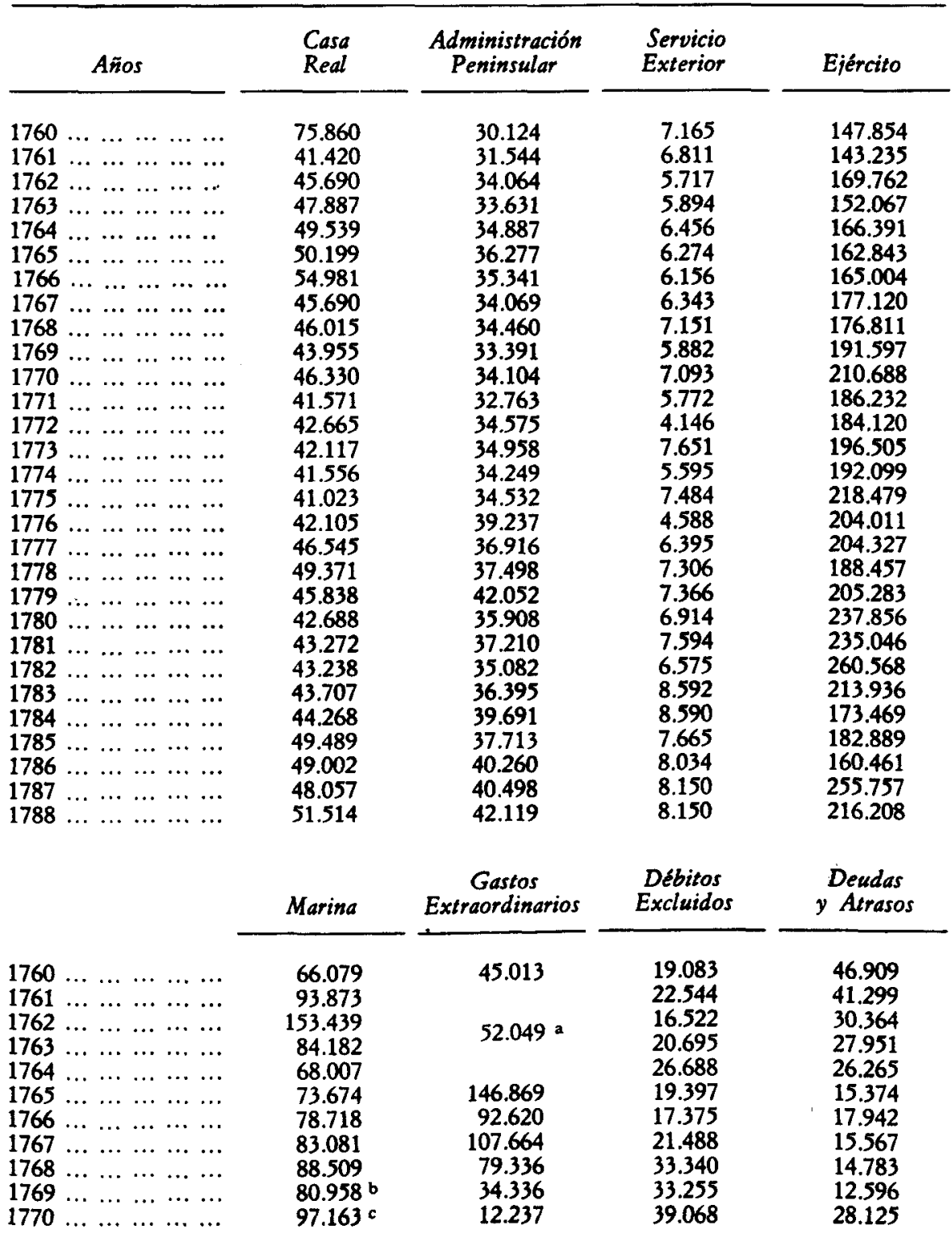


APENDICE 2 (Continuación)

Débitos de la Tesoreria General por grupos de gasto

(En miles de reales de vellón)

\begin{tabular}{|c|c|c|c|c|}
\hline$A \bar{n} o s$ & Marina & $\begin{array}{c}\text { Gastos } \\
\text { Extraordinarios }\end{array}$ & $\begin{array}{l}\text { Débitos } \\
\text { Excluidos }\end{array}$ & $\begin{array}{l}\text { Deudas } \\
\text { y Atrasos }\end{array}$ \\
\hline $\begin{array}{llllll}1771 & \ldots & \ldots & \ldots & \ldots & \ldots \\
1772 & \ldots & \ldots & \ldots & \ldots & \ldots \\
1773 & \ldots & \ldots & \ldots & \ldots & \ldots \\
1774 & \ldots & \ldots & \ldots & \ldots & \ldots \\
1775 & \ldots & \ldots & \ldots & \ldots & \ldots \\
1776 & \ldots & \ldots & \ldots & \ldots & \ldots \\
1777 & \ldots & \ldots & \ldots & \ldots & \ldots \\
1778 & \ldots & \ldots & \ldots & \ldots & \ldots \\
1779 & \ldots & \ldots & \ldots & \ldots & \ldots \\
1780 & \ldots & \ldots & \ldots & \ldots & \ldots \\
1781 & \ldots & \ldots & \ldots & \ldots & \ldots \\
1782 & \ldots & \ldots & \ldots & \ldots & \ldots \\
1783 & \ldots & \ldots & \ldots & \ldots & \ldots \\
1784 & \ldots & \ldots & \ldots & \ldots & \ldots \\
1785 & \ldots & \ldots & \ldots & \ldots & \ldots \\
1786 & \ldots & \ldots & \ldots & \ldots & \ldots \\
1787 & \ldots & \ldots & \ldots & \ldots & \ldots \\
1788 & \ldots & \ldots & \ldots & \ldots & \ldots\end{array}$ & $\begin{array}{l}102.203^{d} \\
90.168^{\circ} \\
81.585^{\circ} \\
87.585^{\prime} \\
109.757^{\circ} \\
152.876^{\circ} \\
128.033^{\circ} \\
153.925^{\mathrm{h}} \\
137.378^{\circ} \\
231.231^{\circ} \\
180.710^{\circ} \\
247.857^{\mathrm{k}} \\
194.224^{\prime} \\
177.709^{\mathrm{m}} \\
164.041^{\mathrm{n}} \\
145.017^{\circ} \\
144.299^{\mathrm{p}} \\
158.522^{\circ}\end{array}$ & $\begin{array}{r}13.876 \\
17.152 \\
20.159 \\
20.550 \\
20.135 \\
29.343 \\
24.358 \\
29.795 \\
23.934 \\
179.854 \\
29.380 \\
68.811 \\
77.653 \\
37.276 \\
60.851 \\
39.214 \\
27.371 \\
42.908\end{array}$ & $\begin{array}{l}21.023 \\
23.362 \\
27.685 \\
23.548 \\
28.147 \\
28.636 \\
33.952 \\
32.517 \\
30.983 \\
33.874 \\
40.989 \\
33.368 \\
33.750 \\
40.676 \\
47.044 \\
49.367 \\
48.910 \\
42.235\end{array}$ & $\begin{array}{r}42.448 \\
34.799 \\
5.503 \\
11.729 \\
9.337 \\
14.021 \\
21.274 \\
39.103 \\
23.352 \\
31.042 \\
120.378 \\
61.941 \\
58.049 \\
87.824 \\
86.370 \\
66.092 \\
68.127 \\
86.278\end{array}$ \\
\hline
\end{tabular}

FuENTE: Archivo General de Simancas, Dirección General del Tesoro, Inventario 16, Guión 3, Legs. 1-12.

Notas:

a Véase cuadro 1, nota b. Las cifras originales, antes de suprimir los 270 millones de reales de vellón, eran: $1761,240.724 .523 ; 1762,33.492 .494 ; 1763,77.644 .955$, y $1764,126.331 .232$.

b De los que 3 millones de reales de vellón eran para Ceuta.

c De los que 57.760 reales de vellón eran para la costa de Granada.

d De' los que 248.682 reales de vellón eran para la costa de Granada.

e De los que 108.090 reales de vellón eran para la costa de Granada.

De los que 220.000 reales de vellón eran para la costa de Granada.

* De los que 149.600 reales de vellón eran para la costa de Granada, y otros 1.512.605 para una expedición.

h Este incluye como gasto naval aparte la suma de 118.068 reales de vellón que fueron enviados a la fábrica de Liérganes.

i De los que 127.800 reales de vellón eran para la costa de Granada.

j De los que 15.000 reales de vellón eran para la costa de Granada, y otros 9.754 .770 para Menorca o Mahón.

k De los que 9.000 reales de vellón eran para la costa de Granada, y otros 11.014 .718 para Menorca.

1 De los que 3.741.788 reales de vellón eran para Menorca.

$m$ De los que 2.168.470 reales de vellón eran para Menorca.

$n$ De los que 3.436.041 reales de vellón eran para Menorca.

- De los que 3.783.097 reales de vellón eran para Menorca.

p De los que 3.261.958 reales de vellón eran para Menorca.

a De los que 2.734.516 reales de vellón exan para Menorca. 


\section{BIBLIOGRAFIA}

Artola, M. (1982): La Hacienda del Antiguo Régimen, Madrid, Alianza.

Artola, M., y Bilbao, L. M. (eds.) (1984): Estudios de Hacienda: de Ensenada a Mon, Madrid, Instituto de Estudios Fiscales.

BARBIER, J. A. (1977): "The Culmination of the Bourbon Reforms, 1787-1792», Hispanic American Historical Review, núm. 1, pp. 51-68.

- (1980): «Peninsular Finances and Colonial Trade: The Dilemma of Charles IV's Spain», Journal of Latin American Studies, núm. 1, pp. 21-37.

- (1981): "Venezuelan "Libranzas", 1788-1807: From Economic Nostrum to Fiscal Im. perative», The Americas.

Barbier, J. A., y Klein, H. (1981): «Revolutionary Wars and Public Finance: the Madrid Treasury, 1784-1807", The Journal of Economic History, núm. 2, pp. 315-339.

CANGa Argüelles, J. de (1826-1827): Diccionario de Hacienda, Londres, 5 vols.

Cuenca, J. (1981): “Ingresos netos del Estado español, 1788-1820», Hacienda Pública Española, núm. 69, pp. 183-208.

Fontana, J. (1973): Hacienda y Estado en la crisis final del Antiguo Régimen español, 1823-1833, Madrid, Instituto de Estudios Fiscales.

- (1974): La quiebra de la Monarquía Absoluta, 1814-1820, Barcelona, Ariel.

González Enciso, A., y Merino, J. P. (1979): "The Public Sector and Economic Growth in Eighteenth Century Spain», Journal of European Economic History, núm. 8.

Hamilton, E. J. (1947): War and Prices in Spain, 1651-1800, Cambridge, Mass.

HerR, R. (1958): The Eighteenth Century Revolution in Spain, Princeton.

Lewis, J. A. (1980): «Las Damas de La Habana, el Precursor and Francisco de Saavedra: a note on Spanish Participation in the Battle of Yorktown», The Americas, núm. 1, pp. 83-89.

Matilla Tascón, A. (1950): Catálogo de las órdenes generales de rentas, Madrid.

Merino, J. P. (1981): «La Hacienda de Carlos IV», Hacienda Pública Española, núm. 69, pp. 139-181.

Ozanam, D. (1966): «Le système fiscal espagnol sous Charles III d'après un document contemporain», Mélanges à la mémoire de Jean Sarrailh, París, 2 vols.

Ringrose, D. (1973): «Perspectives on the Economy of Eighteenth Century Spain», Historia Ibérica, núm. 1, pp. 59-101.

StEIN, S. J., y H., Barbara (1973): *Conceps and Realities of Spanish Economic Growth», Historia Ibérica, núm. 1, pp. 103-119. 